Article

\title{
Prospective Smart Distribution Substation in Bangladesh: Modeling and Analysis
}

\author{
Abdul Hasib Siddique ${ }^{1}\left(\mathbb{D}\right.$, Mehedi Hasan ${ }^{2,3}{ }^{(D)}$, Sharnali Islam ${ }^{4}$ and Khalid Rashid ${ }^{5, *}$ \\ 1 Department of Electrical and Electronic Engineering, The International University of Scholars, \\ Dhaka 1230, Bangladesh; ahnion.ahs@gmail.com \\ 2 Department of Electrical and Computer Engineering, North South University, Dhaka 1229, Bangladesh; \\ mehedi.hasan01@northsouth.edu or mehedihasan261996@gmail.com \\ 3 Department of Electrical and Electronic Engineering, University of Science and Technology Chittagong, \\ Chattogram 4202, Bangladesh \\ 4 Department of Electrical and Electronic Engineering, University of Dhaka, Dhaka 1000, Bangladesh; \\ sharnali.eee@du.ac.bd \\ 5 Department of Chemical Engineering, University of Delaware, Newark, DE 19716, USA \\ * Correspondence: khalidr@udel.edu
}

Citation: Siddique, A.H.; Hasan, M.; Islam, S.; Rashid, K. Prospective Smart Distribution Substation in Bangladesh: Modeling and Analysis. Sustainability 2021, 13, 10904. https://doi.org/10.3390/ su131910904

Academic Editor:

Samuel Asumadu-Sarkodie

Received: 5 April 2021

Accepted: 28 June 2021

Published: 30 September 2021

Publisher's Note: MDPI stays neutral with regard to jurisdictional claims in published maps and institutional affiliations.

Copyright: (c) 2021 by the authors. Licensee MDPI, Basel, Switzerland. This article is an open access article distributed under the terms and conditions of the Creative Commons Attribution (CC BY) license (https:// creativecommons.org/licenses/by/ $4.0 /)$.

\begin{abstract}
Being one of the fastest-growing economies in the world, Bangladesh needs to upgrade its electrical network and aim to reduce dependency on fossil fuel-based energy. For the aging and ever-expanding power network, it is necessary to have a smart substation in order to provide reliable, affordable, and sustainable electrical power. As Bangladesh is looking to integrate Distributed Generation (DG) in the power system, it is high time to think about integrating a smart distribution substation into its power network. In this paper, an investigation of the current power generation structure of Bangladesh was conducted and is described. The major focus was given to the upgradation of the existing substation and distribution setup of Bangladesh by providing suitable architectures, technologies, and communication protocols. Detailed studies of Bangladesh's prospects to incorporate the new technology and renewable energy into its power network are discussed. ETAP was used to simulate the prospective system to show the feasibility of the prospective smart distribution substation in Bangladesh's power network.
\end{abstract}

Keywords: smart substation; smart distribution; distributed generation; energy security; distribution network; ETAP

\section{Introduction}

The present-day world requires energy in vast quantity to retain its progress in the massive development activities. This energy demand keeps on increasing at a substantial rate due to the ever-increasing population. To cope with the rapidly increasing energy demand, the energy systems in the future need to be updated with modern technologies. The two key issues associated with the future energy systems are the integration of an immense number of renewable energy sources into the grid and the delivery of active demand from the customer standpoint. These two issues have patronized the necessity of implementing a smarter grid that can deal with high coincidence factors without having massive structural changes in the exiting grid.

As per the analogy of various researchers, it is quite certain that future transmission systems will likely remain the same. On the contrary, the low voltage distribution network ought to be quite different from the existing ones in order to maintain power quality and to accommodate a large number of distributed generation sources [1].

Hence, from the distribution point of view, the future power scenario holds a very different picture than what exists today. In the future, systems ought to be self-supporting in all the areas, which include rural, urban, and even industrial energy setups [2]. The various new power generation sources utilizing different technologies ought to give a new 
perspective to the distribution network [3]. Furthermore, a two-way power flow network will be the key demand for a developing nation like Bangladesh. Hence, consumers will be able to consume power from the network and sell surplus power generated from distributed generation.

Bearing in mind the future smart and intelligent power grid operation, it is imperative to opt for the most secured power system network using the resources available in Bangladesh $[4,5]$. As a result, technologies such as IoT will play a pivotal role in realizing tomorrow's energy grid. IoT will lead the pack in order to make the network robust [6].

For a developing country like Bangladesh, the electrical demand was always greater than the generation capacity [7]. Although Bangladesh has come a long way in the last decade, there is still ample room for improvement [8]. Therefore, in order to cope up with the rapidly escalating electrical demand, attention needs to be given to generating electricity through DGs. Keeping this in mind, Bangladesh is moving towards DG and the concept of the microgrid has become popular especially in rural Bangladesh. Rural areas in Bangladesh encounter a huge power outage and the solar home system (SHS) is playing a pivotal role to overcome this shortage of electricity [9].

Looking at the urban setup, a smart substation is a potential solution to Bangladesh's problem. Meanwhile, IoT and big data can be implemented to understand the effectiveness and feasibility of such systems in Bangladesh [10]. The main goal of this study is to analyze the prospective architecture of smart distribution substation and IoT-based distribution grid from Bangladesh's perspective. Barriers in integrating smart substation and distribution system with the existing power infrastructures in Bangladesh were explored and possible solutions are provided. In addition, control methods and structure of smart substation and distribution process are provided. In short, the major contributions of this research are:

- Analysis for the need of a smart substation in Bangladesh;

- $\quad$ Outline the renewable energy potential in Bangladesh;

- $\quad$ Detailed single-line diagram (SLD) of the proposed $33 \mathrm{kV} / 11 \mathrm{kV} / 110 \mathrm{~V}$ distribution substation for the prospective substation architecture;

- Control and communication for smart distribution substation;

- $\quad$ Generic object-oriented substation events (GOOSE) messaging for better communication;

- A four-layer substation architecture and justification of its use;

- $\quad$ ETAP simulation for the proposed prospective substation architecture of Bangladesh;

- Use of smart remote terminal unit (RTU) sensors for SCADA control;

- $\quad$ IoT and its use in distribution network with respect to Bangladesh.

\section{Existing Power Scenario of Bangladesh}

In Bangladesh, natural gas is the main source of energy generation [11]. As per the annual report of Bangladesh Power Development Board (BPDP) [12], a detailed distribution of Bangladesh's power sector in 2017-2018 and 2018-2019 is shown in Figure 1. As seen in Figure 1, the major sources of the power generated in Bangladesh are obtained using natural gas is due to the large reserve of natural gas. However, with the current natural gas consumption of 142 million cubic feet per day, the natural gas reserve in Bangladesh will be exhausted by 2031 [13]. Hence, exhausting the major source of power generation is a substantial concern for Bangladesh.

With a careful investigation of Figure 1, it is evident that more focus is given on renewable energy sources in contemporary years [14]. With the huge surge in demand, Bangladesh opted for quick rental in power plants. Currently, Ashuganj Power Station Company Limited, Electricity Generation Company of Bangladesh Limited, North West Power Generation Company Limited, Power Grid Company of Bangladesh Limited, West Zone Power Distribution Company Limited, and Northern Electricity Supply Company Limited are producing electricity on behalf of BPDB. 


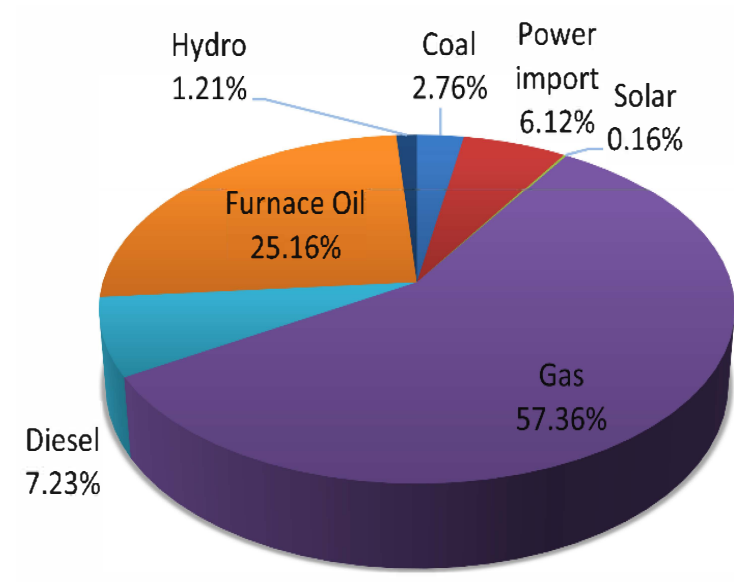

$2018-2019$

- Coal $\square$ Power import $\square$ Solar

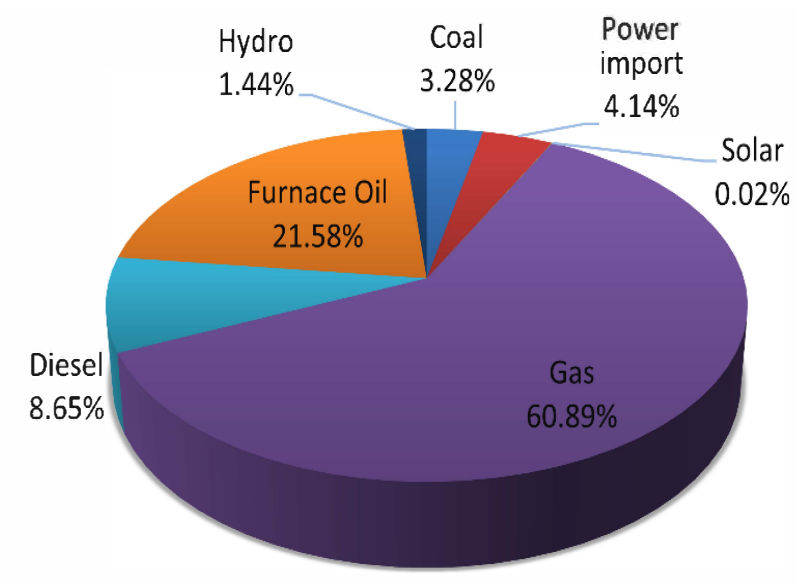

$2017-2018$

Figure 1. Power generation percentage of Bangladesh as per energy sources [12,13].

Looking at the load analysis of Bangladesh, it is easily realized that most of the loads in the country are very basic (such as lights, fans, etc.). These loads constitute around 50\% of the total power consumption [15]. On the other hand, the $\mathrm{CO}_{2}$ emission rate (metric tons per capita) has already increased rapidly from 0.2 for the year 2005 to 0.51 for the year 2016, and it has been increasing ever since [16]. Hence, it is high time for Bangladesh to shift its focus from fossil fuel to renewable energy sources.

It is evident from [17] that there is a steady rise in demand and generation of electricity. Since 2010, the power sector of Bangladesh has seen rapid development. Bangladesh saw the most progress in power generation in the year 2013-2014 [17]. During this period, a total of $1545 \mathrm{MW}$ was added to the grid, which increased the capacity by almost $16 \%$. In addition to this, $500 \mathrm{MW}$ of power was imported from India [18].

In 2019, the system loss was about 7.3\%, which is a significant percentage of Bangladesh's generation capacity. System loss is a persistent problem in Bangladesh's infrastructure, which is affecting the public utilities. One more issue that needs to be tackled is the aging power transmission system. Keeping in mind all the challenges, Bangladesh needs to reduce its overwhelming dependency on fossil fuels (natural gas, oil, and coal). Renewable energy sources such as biomass, biogas, solar, hydropower, and wind are the potential substitutes that Bangladesh can focus on now.

Bangladesh is also all set to incorporate nuclear energy into the national grid as early as 2024 with VVER-1200 reactors [19]. By completing this project, Bangladesh will become the 33rd nuclear power producer in the world with an estimated cost of 2.5 billion USD.

Even though Bangladesh has a great potential to integrate renewable energy, none of the existing distribution substations are capable of handling it. Figure 2 shows a 33/11 kV used by BPDB in Chattogram. In this section, typical substation architecture is studied. The substation has both a $33 \mathrm{kV}$ bus and $11 \mathrm{kV}$ bus. From the $33 \mathrm{kV}$ bus, a subline goes out towards Fouzderhat substation. Two vacuum circuit breakers (VCB) of the rating $1250 \mathrm{~A}$ and $800 \mathrm{~A}$ are connected for the power flow. The transformer rating is considered to be 16/20 MVA, which is connected to an $11 \mathrm{kV}$ bus via one air circuit breaker (ACB) of the rating $1250 \mathrm{~A}$. The load feeders are passed through a ACB of the rating $3600 \mathrm{~A}$, keeping in mind a maximum load of $2.5 \mathrm{MW}$. 


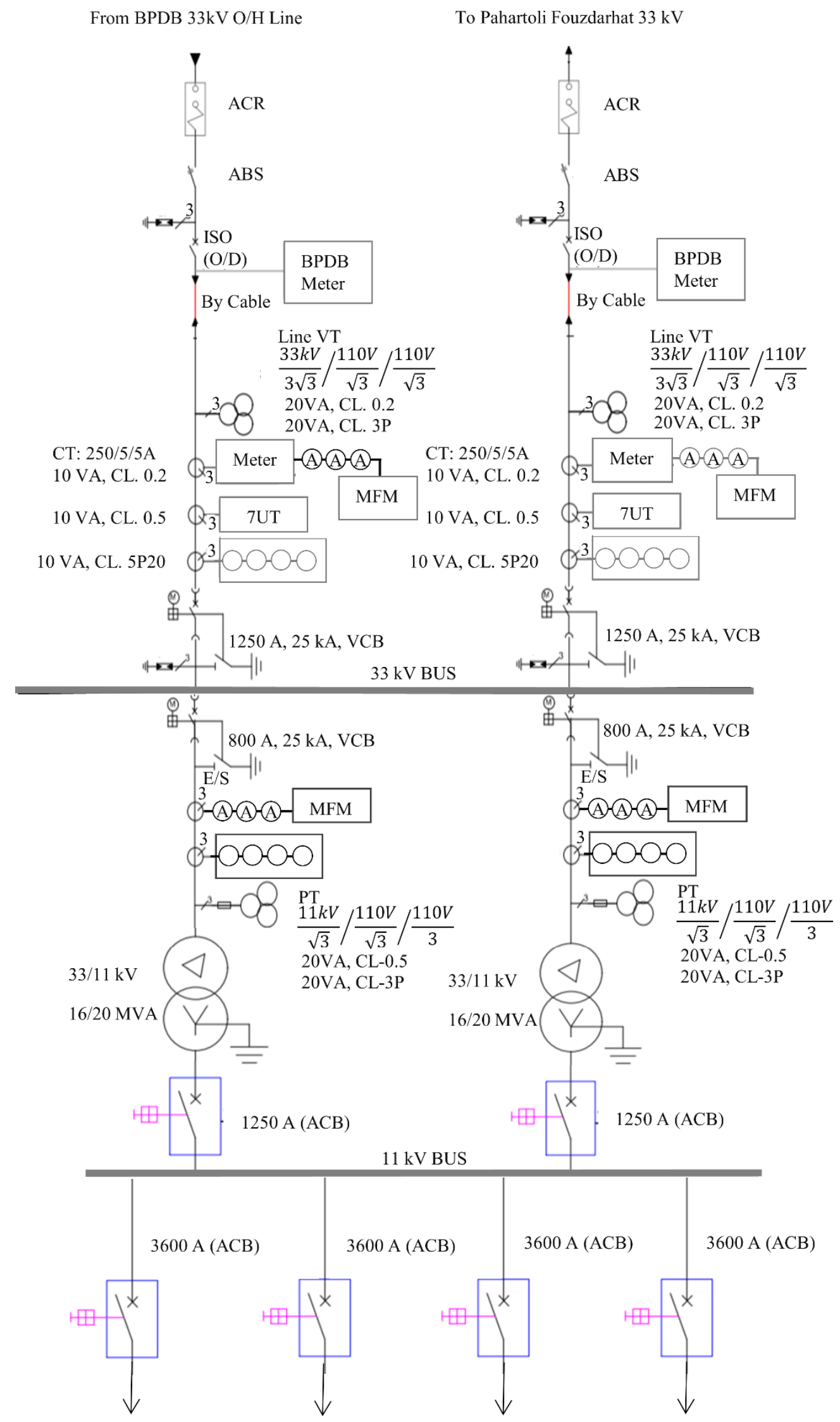

Figure 2. SLD of Fouzderhat 33/11 kV substation in Chattogram, Bangladesh. 


\section{Preliminary Concepts and Background Study}

Bangladesh, being an under-developed country, has many challenges towards upgrading the power system. The extensive surveys in $[20,21]$ provide a clear understanding of the challenges in implementing a smart substation in Bangladesh. Feeder operation and transmission automation in [22] have given the idea of exactly where the automation needs to come on. It is clearly evident that the least automation is present in the distribution network. This would actually affect the DG integration to the system. A three-layer architecture is proposed in [23], which is the main backbone in providing a prospective four-layer architecture in this work. The proposed four-layer system adds a cloud server to gather the data for performing data analysis by a genetic programming-based analysis system. In [24], the future trend and framework were gathered, which helped to understand the communication of the substation. An understanding of incorporating IoT in substations was gathered and implemented by considering the constraints of Bangladesh in mind. A full techno-economic and landscape idea for the substation was gained from [25].

\subsection{Challenges of Smart Substation Implementation}

Many countries face a huge challenge while implementing and upgradation a substation on their existing network. Due to this fact, it is of utmost importance to understand the challenges that Bangladesh might face while doing this transformation from an age-old substation to an updated, modern, smart substation.

India and its challenge to go towards a smart substation and grid are outlined in [25]. A detailed techno-economic evaluation is also discussed in the paper. On the other hand, a next-generation substation has been discussed in several other works, which provide an understanding of data collection in smart substations [26]. The importance of one single communication protocol, IEC 61850, for full substation control is highlighted. In [26], the concept of the process bus and the challenges related to its implementation are discussed. In [27], the promises and challenges of the smarter grid are discussed. In this work, a detailed investigation is done on communication for the smart substation and challenges related to its implementation. Several communication technologies are studied in this paper to understand and evaluate the problems related to each technology. Security is also one of the prime focuses in this work [27].

\subsection{Distribution Network and Substation}

Another important aspect that ought to be discovered is the distribution network architecture and the challenges that it poses. The policy of DG integration and the readiness of the network on IoT implementation need to be studied.

A whole understanding of the distribution system operation for next-generation operation in European countries was outlined in [28]. The report outlines the total distribution network for all the countries in EU. Moreover, the policies and other facts are analyzed. On the other hand, Reference [29] focuses on the distribution station monitoring system of Nigeria. Several IoT-based monitoring systems are outlined in this paper. The structure of the IoT network and step-by-step process of the design factor are pointed out in the work. In [23], the distribution network and substation implementation are discussed in detail.

\subsection{Country-Wise Classification}

Country-wise classification is one of the most important aspects for the background study of this paper. There are several solutions that look amazing but might not provide a fruitful solution for a country like Bangladesh. Hence, looking at the solution for different countries is quite helpful to decide on the features of the substation.

An outline of the potentiality of a smarter grid in Nigeria is provided in [30]. It outlines how the economic condition has been affecting the power network in the country. In another work, a smarter grid implementation is discussed from the perspective of Pakistan [31]. The paper focuses on the challenges associated with transmission and distribution grid implementation. The paper also gives an overview of the current power 
structure of Pakistan and how it could shape the power scenario if a smarter distribution and transmission grid is implemented. Researchers in [25] outline the techno-economic understanding from an Indian standpoint. The paper touches the current technical knowledge and the way forward for India to reach its goal of implementing smart grid all over the country. Researchers in [32] focus on the Moroccan perspective for implementing smart distribution grid. The Middle Eastern case is described in [32]. There is a plan for the expansion of Middle-Eastern grid beyond the boundaries of each nation. This paper describes the interconnection of the line. The SLD of the substation and interconnection are outlined in this work for a better understanding of how the system ought to work.

\subsection{Impact of Smart Substation from Economic and Environmental Standpoint}

The research initiative in [25] outlines the economic and technical challenges associated with implementing a smart substation. At the same time, it also indicates the benefit that it can bring from an economic standpoint. In [33], the authors describe the suitable location for the implementation of the smart substation from a techno-economic standpoint. It describes the ideal location for $400 \mathrm{kV}$ transmissions to $66 \mathrm{kV}$ distribution substations. In another work, a case study in India was conducted to understand the impact of step land construction for the substation. Moreover, in [34], a techno-economic aspect is discussed. This time, the German power network is discussed in detail. This paper outlines both the transmission and low voltage distribution.

\subsection{Challenges in Upgrading the Existing Structure}

There are many pieces of research that have dealt with upgrading the existing substation. Researchers in [35] provided the guidelines for the improvement and modernization of existing substations. This upgradation would include IoT and other smart devices. Intelligent electronic devices (IED), integrated intelligent terminal (IIT), and a three-layer system are described in [35]. A broad description of the substation solution for smart electrical distribution is given in [36]. Few very interesting features are discussed in [36]. Thermal remote online detection and power rush repair command are a few to mention. In [37], the work focuses on the substation upgradation using mixed integrated programming. It focuses on the investment cost and presents an optimized solution. This paper is very important to choose the component suitable for our solution.

\subsection{Protection, Monitoring, Standards, and Security}

For Bangladesh, monitoring, security, and protection are the utmost important factors. Power theft, unwanted personal entrance, and substation efficiency are some of the major issues. Many of the substations in Bangladesh have serious security issues. Hence, to propose a suitable substation in Bangladesh, it is important to consider these factors.

The research initiative in [38] completely focuses on designing a substation for tomorrow. The paper focuses on the protection and monitoring system for a smart substation. A detailed outline on functional features is prioritized in this work. Smart sensing, measurement, communication network protocol, autonomous control, adaptive protection, data management, monitoring, alarming, diagnosis, advanced interfaces with DGs, real-time modeling, and cyber security are the main points of discussion. In another work, the basic concept and features of smart substations are discussed [39]. In this work, all the technical features of the substation are discussed in detail. This includes IEC 61850 (which is the proposed protocol for this work as well), the human-machine interface (HMI), GOOSE, IED, and IIT.

\section{Electrical Substation in Power Network: A Perspective of Bangladesh}

Considering all the renewable energy potential of Bangladesh, it can be perceived that the most suitable form of a smart grid is a combination of solar and wind power and to some extent micro-hydro power. Solar power is the most prominent source of renewable energy in Bangladesh. In order to incorporate solar-wind hybrid units in the system, it is 
important to think about a smart distributed substation that will be responsible for keeping the record of all events to perform predictive analysis for the renewable energy sources. As the outputs obtained from renewable energy sources fluctuate, it is quite important to have a central predictive analysis center. There are many predictive models that could suit the data obtained from the environmental agency. Several methods such as the auto-regressive model, multi-aspect analysis, time series decomposition, and predictive clustering model have been studied. However, for the simplicity of operation, genetic programming-based predictive analysis is taken into consideration. This could easily take the input vector and predict the output discarding the outliers. Again, the output of the recently generated one would be considered to generate the subsequent outputs.

These predictive analyses would take place in the central database, and a smart substation can bring about the central database solution for a country like Bangladesh, where thinking about a fully operational smart grid is still a farfetched dream. In order to handle this big amount of data and to obtain accurate prediction, a comprehensive and easy data-hosting technique is required to be adopted [40]. SPARK, HADOOP, and AWS were looked into closely. Memory cluster computing-based SPARK ought to be used for the data hosting. This will enhance the speed and help to analyze the data. This will help Bangladesh to incorporate renewable energy in the national grid and harness the potential to maximize the renewable energy output.

All the national grids constitute a grid code. To accommodate new distributed generation units, the grid codes need to be revised in the case of Bangladesh. The power generation mix is changing at a rapid speed, and the new dynamics of the generation units vary widely from that of the past. The unpredictability and smaller size of energy sources bring about a challenge to the existing distribution system. Especially, this needs to be done to tackle the frequency issue that comes with DGs. On the one hand, solar energy produces DC, whereas hydro and wind produce AC. Therefore, intermittency and deviations must be controlled so that system stability can be maintained. ENTSO-E grid codes can be implemented in the process layer of the distributed substation. Wind power units can be directly connected to the substation, and solar can be easily put through a converter and match the grid code at the generation place.

There are mainly four types of substations in a power network of Bangladesh: (a) switchyard substation, (b) customer substation, (c) system substation, and (d) distribution substation. Switchyard substations are usually placed in generating stations that connect the generators to the utility grids. Moreover, switchyard substations provide offset power to the power plants. They are very different from a common substation that can be seen in the cities or nearby localities. This sort of substation operates on a single voltage level without incorporating a transformer. Switchyard substations are used for transmission, distribution, collection, and to control the electricity flow. Customer substations are connected to the transmission line, which is connected to the power plants. This type of substation is usually designed for feeding the demand of a specific customer. The specific customers are mainly factories and industries. System substations are usually placed at the end of the transmission line. This kind of substation provides a switching and voltage conversion. A distribution substation is a localized distribution unit feeding a defined area with a specific voltage level. It is very uneconomical and less efficient to connect a user to the main transmission network.

From the perspective of Bangladesh, distribution substations are the main blocks where major changes will occur. Traditional distribution substations will be updated with smart and intelligent infrastructures. Solar energy obtained from SHS, energy from solar plants, and wind farms are going to be connected to the distributions substation. Especially for a country like Bangladesh, this type of substation is important, as intelligent devices are not present at the consumer end. This type of substation can also isolate the fault and act as a data center for the DGs. The ENTSO-E grid code can be implemented through this substation. A smart distributed substation can act as a center for controlling all DGs in Bangladesh. The on-off sequence and two-way power transfer can also be followed up at this center. 
Existing substations only step down the voltage to the customer level of $11-33 \mathrm{kV}$ and have no intelligent device in the system. On the other hand, the proposed prospective distributed smart substation ought to be fully automated, and several intelligent devices will be present to make DG integration and bidirectional power flow possible.

\section{Prospective Smart Substation and System Integration Method for Bangladesh}

In Figure 3, keeping the constraints of Bangladesh in mind, a detailed description of the smart substation's single-line diagram (SLD) is given. Bangladesh still has the transmission voltage at $230 \mathrm{kV}$. Hence, by identifying the lack of automated devices in the existing substation, a simple $33 / 11 \mathrm{kV}$ substation with $415 \mathrm{~V}$ feeders is proposed. In the existing BPDB substations of Bangladesh, there are no $415 \mathrm{~V}$ feeders, which can be connected to the DGs. Keeping this limitation in mind, a micro $415 \mathrm{~V}$ bus is proposed, which would be connected to the $11 \mathrm{kV}$ bus via the ADLINE phase-locked loop (PLL).

The ADALINE PLL was chosen for its robust performance in the case of harmonics. The overhead HT line ought to be connected to the $33 / 11 \mathrm{kV}$ transformer through a line isolator. This would go to a VCB of the rating $1250 \mathrm{~A}$. The output of the transformer would be fed into a $11 \mathrm{kV}$ bus, which ought to be connected to both the DG generation and load dispatch center by a tiebreaker. The feeders at the load dispatch center are connected to the VCB, current transformer (CT), and potential transformer (PT). Each of the feeders is connected to these protective devices.

The PV array is mounted with a maximum power point tracker (MPPT) and photo sensor IoT devices. These would be remotely connected to the data hosting servers. Besides, IoT devices will be connected to the breakers, and temperature sensors will be implemented in the transformers. For the wind, a similar approach should be taken, where wind speed and wind direction are constantly monitored by IoT devices. Control, data storing, and power lines are detailed in Figure 3. The new grid code should be added to automate the substation, which is able to detect the earth fault and localize a mix of all the components. Besides, an IEEE 61850-based high-speed fiber optics cable was selected, which would be installed in the substation for measurement and control of the breakers. Both supervisory control from the control room and remote access would be established to control the functions. The blue lines in Figure 3 denote the SCADA function. Both the SV and GOOSE network would do the communication, which is present in the Bay layer. The orange line in Figure 3 shows the flexible resources in the low voltage (LV) side network. The orange block represents the IoT devices in the substation. Data should be collected by the IoT devices and sent to the cloud server for big data hosting by SPARK. The huge data collected by the end nodes is then processed, and a predictive analysis would thus be available at the central substation server. All the IEDs would also be connected to the server, which is denoted by green line.

In the proposed prospective substation, SCADA communication would be done using TCP/IP 61850 and TCP/IPIEC-104, which is the standard for smart station control and communication. The following information would then be fetched by using RTU in the SCADA database for smooth and smart operation of the substation.

- Primary data from the equipment;

- Active and reactive power measurements;

- Current and voltage measurements from CT and PT;

- Switching status;

- Transformer regulating the control operation;

- Temperature and thermal scanners;

- Protection relay status;

- Equipment failures status;

- Equipment warnings status;

- Communication information;

- RTU;

- Switches; 
- $\quad$ SCADA bus status.

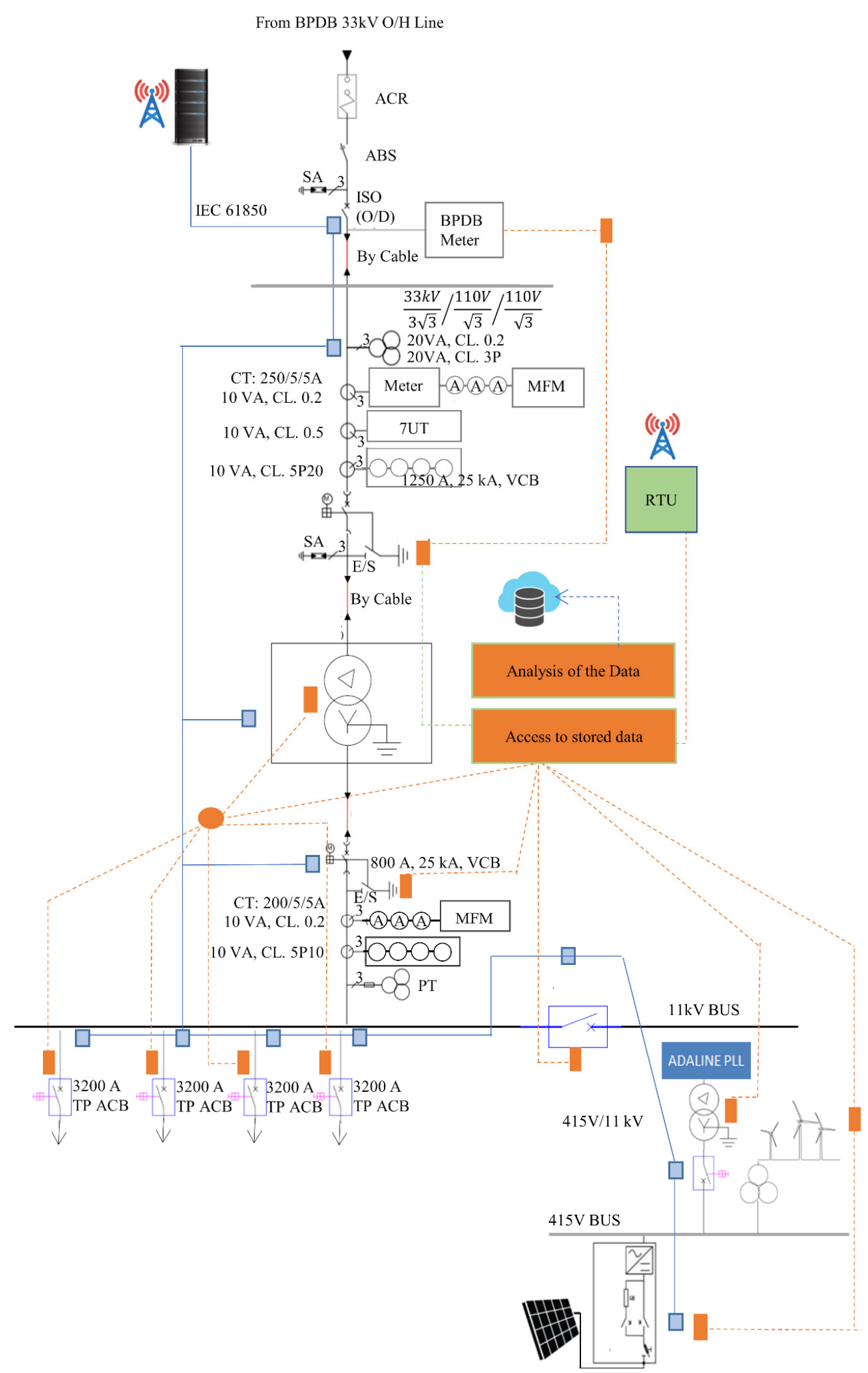

Figure 3. SLD of the smart distribution substation. 
The proposed prospective smart substation was simulated using ETAP. For the analysis of the substation, a total of 13 buses were considered. The transformer, line, and tie branches were taken to be 16. Figure 4 shows the ETAP diagram of the proposed prospective substation. The ETAP diagram in Figure 4 incorporated a 0.5 MW wind power generation plant and $10 \mathrm{MW}$ solar generation plant. Simulation results of the substation are presented in Tables 1-5.

Table 1. Load flow of the substation obtained from the ETAP simulation.

\begin{tabular}{|c|c|c|c|c|c|c|c|c|c|c|c|c|}
\hline \multicolumn{2}{|c|}{ Bus } & \multicolumn{2}{|c|}{ Voltage } & \multicolumn{2}{|c|}{ Generation } & \multicolumn{2}{|c|}{ Load } & \multicolumn{5}{|c|}{ Load Flow } \\
\hline ID & $\mathbf{k V}$ & \%Mag & Ang. & MW & Mvar & MW & Mvar & ID & MW & Mvar & Amp & $\%$ PF \\
\hline Bus1 & 33.000 & 100.000 & 0.0 & 8.265 & -0.325 & 0 & 0 & Bus2 & 8.265 & -0.325 & 144.7 & -99.9 \\
\hline \multirow[t]{3}{*}{ Bus2 } & 33.000 & 99.949 & -0.1 & 0 & 0 & 0 & 0 & Bus1 & -8.361 & 0.154 & 144.6 & -100.0 \\
\hline & & & & & & & & Bus6 & 12.822 & 0.768 & 224.8 & 99.8 \\
\hline & & & & & & & & Bus5 & -4.562 & -0.923 & 81.5 & 98.0 \\
\hline Bus4 & 33.000 & 100.000 & 0.0 & 8.265 & -0.325 & 0 & 0 & Bus5 & 8.265 & -0.325 & 144.7 & -99.9 \\
\hline \multirow[t]{3}{*}{ Bus5 } & 33.000 & 99.949 & -0.1 & 0 & 0 & 0 & 0 & Bus4 & -8.261 & 0.154 & 144.6 & -100.0 \\
\hline & & & & & & & & Bus7 & 3.699 & -1.077 & 67.4 & -96.0 \\
\hline & & & & & & & & Bus2 & 4.562 & 0.923 & 81.5 & 98.0 \\
\hline \multirow[t]{4}{*}{ Bus6 } & 11.000 & 99.360 & -4.7 & 0 & 0 & 0 & 0 & Bus2 & -12.767 & 0.263 & 674.5 & -100.0 \\
\hline & & & & & & & & Bus8 & 4.256 & -0.088 & 224.8 & -100.0 \\
\hline & & & & & & & & Bus14 & 4.256 & -0.088 & 224.8 & -100.0 \\
\hline & & & & & & & & Bus15 & 4.256 & -0.088 & 224.8 & -100.0 \\
\hline \multirow[t]{4}{*}{ Bus7 } & 11.000 & 100.525 & -1.4 & 0 & 0 & 0 & 0 & Bus5 & -3.694 & 1.170 & 202.3 & -95.3 \\
\hline & & & & & & & & Bus9 & 1.231 & -0.390 & 67.4 & -95.3 \\
\hline & & & & & & & & Bus11 & 1.231 & -0.390 & 67.4 & -95.3 \\
\hline & & & & & & & & Bus12 & 1.231 & -0.390 & 67.4 & -95.3 \\
\hline \multirow[t]{2}{*}{ Bus8 } & 0.415 & 99.173 & -7.9 & 0 & 0 & 4.236 & -0.325 & Bus6 & -4.236 & 0.325 & 5959.8 & -99.7 \\
\hline & & & & & & & & Bus14 & 0.000 & 0.000 & 0.0 & 0.0 \\
\hline \multirow[t]{2}{*}{ Bus9 } & 0.415 & 100.910 & -2.4 & 0 & 0 & 4.266 & -0.411 & Bus7 & -1.230 & 0.411 & 1787.5 & -94.8 \\
\hline & & & & & & & & Bus11 & -3.036 & 0.000 & 4186.6 & 100.0 \\
\hline \multirow[t]{3}{*}{ Bus11 } & 0.415 & 100.910 & -2.4 & 0 & 0 & 4.266 & -0.411 & Bus7 & -1.230 & 0.411 & 1787.5 & -94.8 \\
\hline & & & & & & & & Bus9 & 3.036 & 0.000 & 4185.6 & 100.0 \\
\hline & & & & & & & & Bus12 & -6.072 & 0.000 & 8371.2 & 100.0 \\
\hline \multirow[t]{3}{*}{ Bus12 } & 0.415 & 100.910 & -2.4 & 0 & 0 & 4.266 & -0.411 & Bus7 & -1.230 & 0.411 & 1787.5 & -94.8 \\
\hline & & & & & & & & Bus11 & 6.072 & 0.000 & 8371.2 & 100.0 \\
\hline & & & & & & & & Bus17 & -9.108 & 0.000 & $12,556.7$ & 100.0 \\
\hline \multirow[t]{3}{*}{ Bus14 } & 0.415 & 99.173 & -7.9 & 0 & 0 & 4.236 & -0.325 & Bus6 & -4.236 & 0.325 & 5959.8 & -99.7 \\
\hline & & & & & & & & Bus8 & 0.000 & 0.000 & 0.0 & 0.0 \\
\hline & & & & & & & & Bus15 & 0.000 & 0.000 & 0.0 & 0.0 \\
\hline \multirow[t]{2}{*}{ Bus15 } & 0.415 & 99.173 & -7.9 & 0 & 0 & 4.236 & -0.325 & Bus6 & -4.236 & 0.325 & 5959.8 & -99.7 \\
\hline & & & & & & & & Bus14 & 0.000 & 0.000 & 0.0 & 0.0 \\
\hline Bus17 & 0.415 & 100.910 & -2.4 & 9.108 & 0 & 0 & 0 & Bus12 & 9.108 & 0.000 & $12,556.7$ & 100.0 \\
\hline
\end{tabular}


Table 2. Bus loading of the substation obtained from the ETAP simulation.

\begin{tabular}{|c|c|c|c|c|c|c|c|c|c|c|c|c|}
\hline \multirow{2}{*}{\multicolumn{2}{|c|}{ Bus }} & \multicolumn{8}{|c|}{ Directly Connected Load } & \multirow{2}{*}{\multicolumn{3}{|c|}{ Total Bus Load }} \\
\hline & & \multicolumn{2}{|c|}{ Constant kVA } & \multicolumn{2}{|c|}{ Constant Z } & \multicolumn{2}{|c|}{ Constant I } & \multicolumn{2}{|c|}{ Generic } & & & \\
\hline ID & $\mathbf{k V}$ & MW & Mvar & MW & Mvar & MW & Mvar & MW & MVar & MVA & $\% \mathrm{PF}$ & Amp \\
\hline Bus1 & 33.000 & 0 & 0 & 0 & 0 & 0 & 0 & 0 & 0 & 8.272 & 99.9 & 144.7 \\
\hline Bus2 & 33.000 & 0 & 0 & 0 & 0 & 0 & 0 & 0 & 0 & 12.855 & 99.7 & 225.0 \\
\hline Bus4 & 33.000 & 0 & 0 & 0 & 0 & 0 & 0 & 0 & 0 & 8.272 & 99.9 & 144.7 \\
\hline Bus5 & 33.000 & 0 & 0 & 0 & 0 & 0 & 0 & 0 & 0 & 8.330 & 99.2 & 145.8 \\
\hline Bus6 & 11.000 & 0 & 0 & 0 & 0 & 0 & 0 & 0 & 0 & 12.7 & 100.0 & 674.5 \\
\hline Bus7 & 11.000 & 0 & 0 & 0 & 0 & 0 & 0 & 0 & 0 & 3.875 & 95.3 & 202.3 \\
\hline Bus8 & 0.415 & 3.400 & 2.107 & 0.836 & -2.432 & 0 & 0 & 0 & 0 & 5.162 & 82.1 & 7241.7 \\
\hline Bus9 & 0.415 & 3.400 & 2.107 & 0.836 & -2.432 & 0 & 0 & 0 & 0 & 5.247 & 81.3 & 7233.3 \\
\hline Bus11 & 0.415 & 3.400 & 2.107 & 0.836 & -2.432 & 0 & 0 & 0 & 0 & 7.915 & 92.3 & $10,911.8$ \\
\hline Bus12 & 0.415 & 3.400 & 2.107 & 0.836 & -2.432 & 0 & 0 & 0 & 0 & 10.779 & 95.9 & $14,861.2$ \\
\hline Bus14 & 0.415 & 3.400 & 2.107 & 0.836 & -2.432 & 0 & 0 & 0 & 0 & 5.162 & 82.1 & 7241.7 \\
\hline Bus15 & 0.415 & 3.400 & 2.107 & 0.836 & -2.432 & 0 & 0 & 0 & 0 & 5.162 & 82.1 & 7241.7 \\
\hline Bus17 & 0.415 & 0 & 0 & 0 & -2.432 & 0 & 0 & 0 & 0 & 9.108 & 100.0 & $12,556.7$ \\
\hline
\end{tabular}

Table 3. Branch loading of the substation obtained from the ETAP simulation.

\begin{tabular}{|c|c|c|c|c|c|c|c|c|c|}
\hline \multicolumn{2}{|c|}{ CKT/Branch } & \multicolumn{3}{|c|}{ Cable and Reactor } & \multicolumn{5}{|c|}{ Transformer } \\
\hline \multirow{2}{*}{ ID } & \multirow{2}{*}{ Type } & \multirow{2}{*}{$\begin{array}{c}\text { Ampacity } \\
\text { (Amp) }\end{array}$} & \multirow{2}{*}{$\begin{array}{c}\text { Loading } \\
\text { Amp }\end{array}$} & \multirow{2}{*}{$\%$} & \multirow{2}{*}{$\begin{array}{l}\text { Capability } \\
\text { (MVA) }\end{array}$} & \multicolumn{2}{|c|}{ Loading (Input) } & \multicolumn{2}{|c|}{ Loading (Output) } \\
\hline & & & & & & MVA & $\%$ & MVA & $\%$ \\
\hline Cable1 & Cable & 877.63 & 144.71 & 16.49 & & & & & \\
\hline Cable3 & Cable & 877.63 & 144.71 & 16.49 & & & & & \\
\hline $\mathrm{T} 1$ & Transformer & & & & 20.000 & 12.845 & 64.2 & 12.765 & 63.8 \\
\hline $\mathrm{T} 2$ & Transformer & & & & 20.000 & 3.875 & 19.4 & 3.853 & 19.3 \\
\hline T3 & Transformer & & & & 5.000 & 4.256 & 85.1 & 4.248 & 85.0 \\
\hline $\mathrm{T} 4$ & Transformer & & & & 5.000 & 1.297 & 25.9 & 1.292 & 25.8 \\
\hline T6 & Transformer & & & & 5.000 & 1.297 & 25.9 & 1.292 & 25.8 \\
\hline $\mathrm{T} 7$ & Transformer & & & & 5.000 & 1.297 & 25.9 & 1.292 & 25.8 \\
\hline T9 & Transformer & & & & 5.000 & 4.256 & 85.1 & 4.248 & 85.0 \\
\hline $\mathrm{T} 10$ & Transformer & & & & 5.000 & 4.256 & 85.1 & 4.248 & 85.0 \\
\hline
\end{tabular}

Table 4. Loss summary of the substation obtained from the ETAP simulation.

\begin{tabular}{|c|c|c|c|c|c|c|c|c|c|}
\hline \multirow{2}{*}{$\frac{\text { CKT/Branch }}{\text { ID }}$} & \multicolumn{2}{|c|}{ From-To Bus Flow } & \multicolumn{2}{|c|}{ To-From Bus Flow } & \multicolumn{2}{|c|}{ Losses } & \multicolumn{2}{|c|}{$\%$ Bus Voltage } & \multirow{2}{*}{ Vd\% Drop (Vmag) } \\
\hline & MW & Mvar & MW & Mvar & $\mathbf{k W}$ & kvar & From & To & \\
\hline Cable1 & 8.265 & -0.325 & -8.261 & 0.154 & 4.6 & -170.6 & 100.0 & 99.9 & 0.05 \\
\hline $\mathrm{T} 1$ & 12.822 & 0.768 & -12.767 & 0.263 & 55.4 & 1030.8 & 99.9 & 99.4 & 0.59 \\
\hline Cable3 & 8.265 & -0.325 & -8.261 & 0.154 & 4.6 & -170.6 & 100.0 & 99.9 & 0.05 \\
\hline $\mathrm{T} 2$ & 3.699 & -1.077 & -3.694 & 1.170 & 5.0 & 92.7 & 99.9 & 100.5 & 0.58 \\
\hline $\mathrm{T} 3$ & 4.256 & -0.088 & -4.236 & 0.325 & 19.6 & 237.8 & 99.4 & 99.2 & 0.19 \\
\hline T9 & 4.256 & -0.088 & -4.236 & 0.325 & 19.6 & 237.8 & 99.4 & 99.2 & 0.19 \\
\hline
\end{tabular}


Table 4. Cont.

\begin{tabular}{|c|c|c|c|c|c|c|c|c|c|}
\hline \multirow{2}{*}{$\frac{\text { CKT/Branch }}{\text { ID }}$} & \multicolumn{2}{|c|}{ From-To Bus Flow } & \multicolumn{2}{|c|}{ To-From Bus Flow } & \multicolumn{2}{|c|}{ Losses } & \multicolumn{2}{|c|}{$\%$ Bus Voltage } & \multirow{2}{*}{ Vd\% Drop (Vmag) } \\
\hline & MW & Mvar & MW & Mvar & $\mathbf{k W}$ & kvar & From & To & \\
\hline $\mathrm{T} 10$ & 4.256 & -0.088 & -4.236 & 0.325 & 19.6 & 237.8 & 99.4 & 99.2 & 0.19 \\
\hline $\mathrm{T} 4$ & 1.231 & -0.390 & -1.230 & 0.411 & 1.8 & 21.4 & 100.5 & 100.9 & 0.38 \\
\hline T6 & 1.231 & -0.390 & -1.230 & 0.411 & 1.8 & 21.4 & 100.5 & 100.9 & 0.38 \\
\hline $\mathrm{T} 7$ & 1.231 & -0.390 & -1.230 & 0.411 & 1.8 & 21.4 & 100.5 & 100.9 & 0.38 \\
\hline
\end{tabular}

Table 5. Load, generation, and demand summary of the substation obtained from the ETAP simulation.

\begin{tabular}{|c|c|c|c|c|}
\hline & MW & Mvar & MVA & $\% \mathrm{PF}$ \\
\hline Source (Swing Buses): & 16.530 & -0.650 & 16.543 & 99.92 Leading \\
\hline Source (Non-Swing Buses): & 9.108 & 0.000 & 9.108 & 100.00 Lagging \\
\hline Total Demand: & 25.638 & -0.650 & 25.646 & 99.97 Leading \\
\hline Total Motor Load: & 20.400 & 12.643 & 24.000 & 85.00 Lagging \\
\hline Total Static Load: & 5.105 & -14.853 & 15.705 & 32.50 Leading \\
\hline Total Constant I Load: & 0.000 & 0.000 & 0.000 & \\
\hline Total Generic Load: & 0.000 & 0.000 & 0.000 & \\
\hline Apparent Losses: & 0.134 & 1.560 & & \\
\hline System Mismatch: & 0.000 & 0.000 & & \\
\hline
\end{tabular}

It can be seen that all the bus voltage and load flow analysis are given in Table 1. Tables 2 and 3 provide the bus loading and branch loading of the substation. All the loss summary of the cables and transformer are given in Table 4 . Table 5 shows a summary of the full substation. Both the swing and non-swing bus power factors for the prospective proposed smart substation are quite satisfactory. Moreover, both the static and non-static loads are at a satisfactory level. From the ETAP simulation, is it quite clear that the substation would work perfectly with the proposed equipment.

The SCADA diagram of the DG plant is shown in Figure 5. PV SCADA for the smart substation is situated in $33 \mathrm{kV}$ switching station. Communication modules are connected via MODBUS RS485 to PPC. The ethernet cable junction is also modeled to be situated in this area. All the modules are connected to the switching port. TCP/IP IEC-104 is used in all the communication modules in the switching substation, which are connected to the main metering panel situated in the control room. All the connections of the local switchgear panel and sensors are connected to the switching station. For controlling and communication, TCP/IP IEC-61850 is proposed. This would be connected to the main ethernet port in the main control room. SICAM A8000 is recommended for the controlling and monitoring of the substation for the ease of upgradation from the current system. HMI, CCTV, Switchgear, UPS, fire alarm, and GPS are controlled by this. 


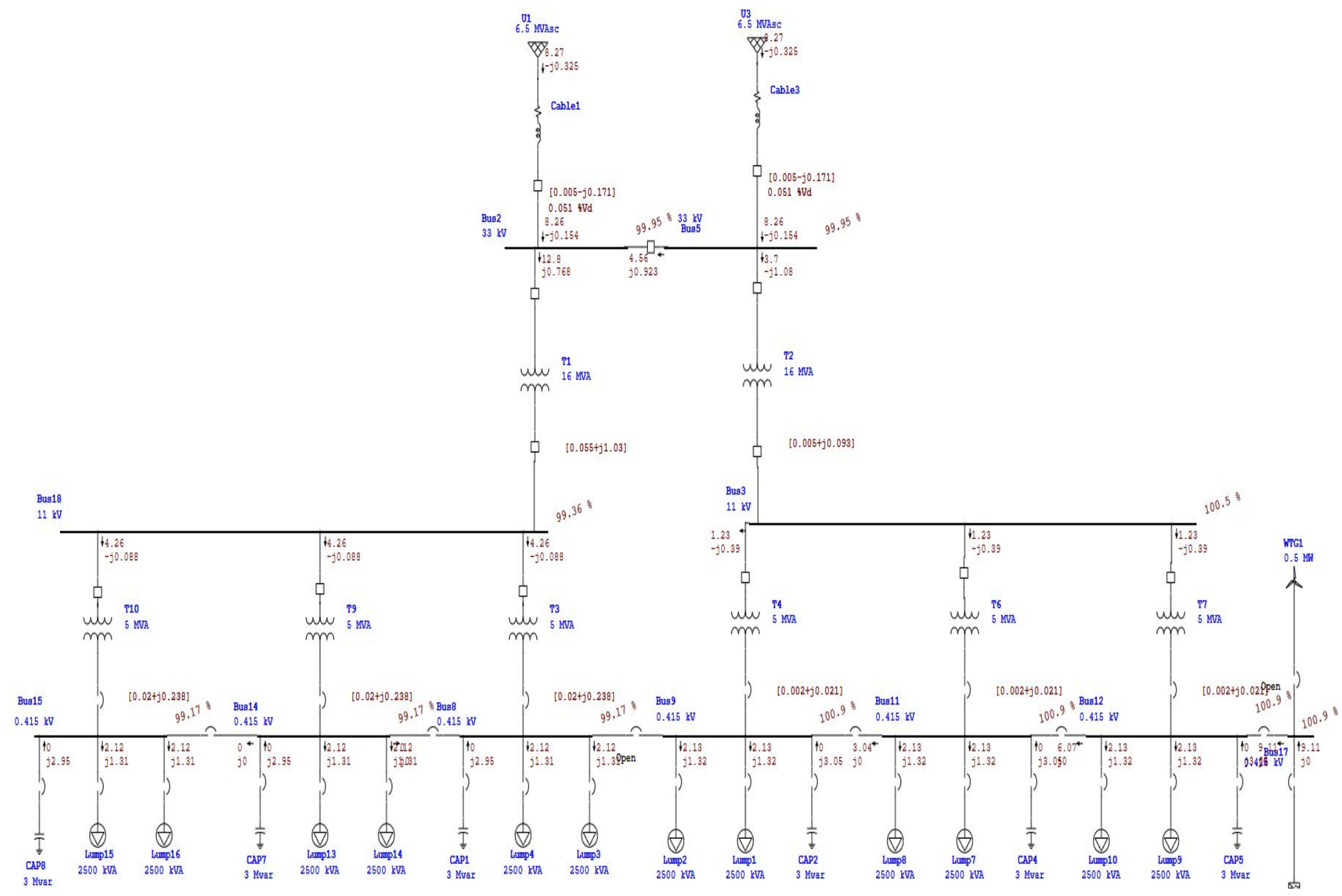

Figure 4. ETAP diagram of the proposed prospective substation with DGs. 


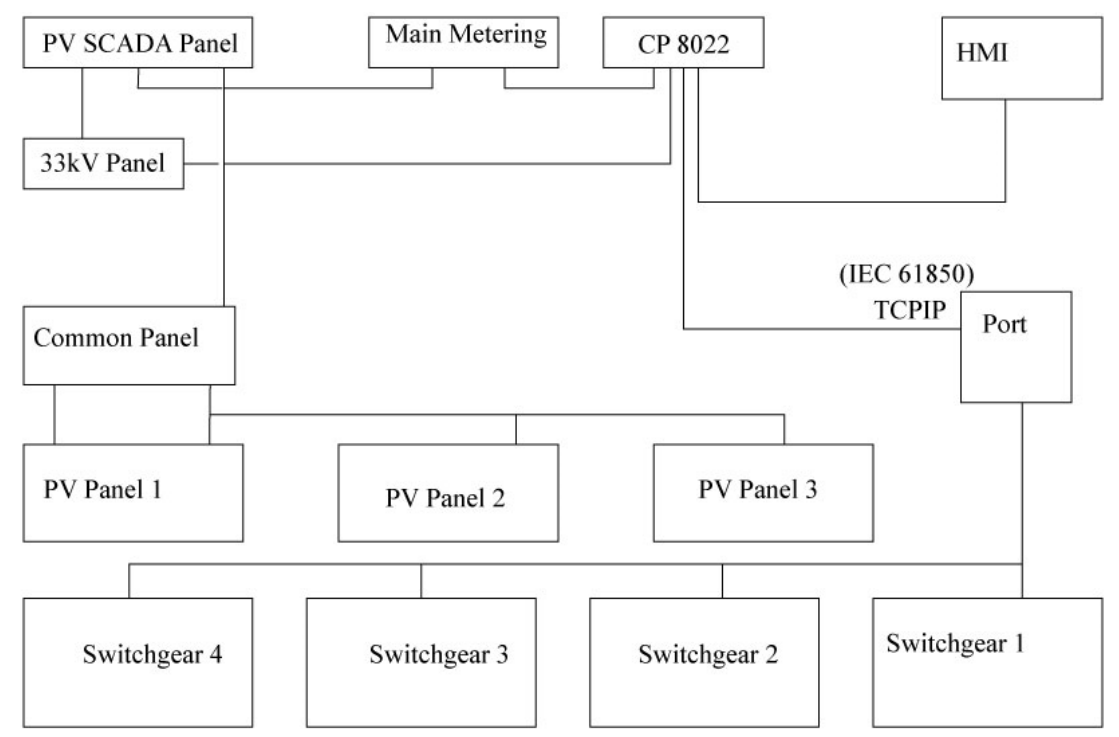

Figure 5. SCADA system for proposed prospective substation.

Looking at the need of the future, a four-layer distributed substation, as represented by Figure 6, would be a suitable solution for Bangladesh. In a distributed substation, usually, a three-layer approach is taken. In the proposed prospective model (Figure 6), an extra layer is taken into consideration in order to accommodate the data analysis of DG and to incorporate the new grid code to tackle the frequency issue posed by DGs. The four layers in the smart substation are the data acquisition layer, process layer, bay layer, and control layer (Figure 6). Smart distributed substations have some extra features as compared to a conventional smart substation or any generic distributed substation. Besides having frequency control and predictive analysis, a smart substation also provides protection, measurement, systems control, and data acquisition. A smart substation also enables identification and self-healing of a faulty system, which increases the control and reliability of Bangladesh's power system.

The major challenges of integrating smart substation are device integration and data synchronization [41,42]. In order to tackle that, integrated master device (IMD) and integrated intelligent terminal (IIT) were considered. The substation layer is the supervisory layer where human-machine interface (HMI) is implemented. The protective system, auxiliary system, state detection, and monitoring systems would be present in this layer. All these controls were integrated into the integrated informational portal (IIP) via a remote communication mode. All these are ought to be monitored and controlled by the HMI, which would be specially designed to reduce direct contact and promote remote supervision. Besides this, the predictive analysis data would be shown in the substation layer and any manual overwrite would be possible through onsite or remote admin access. The bay layer was designed to have IMD, which is responsible for the control of protective equipment, measurements, recording the faults, alarms, and store things in the local server. In the process layer, IIT and merger units are to be integrated into the sampled value (SV) packet transmission network and GOOSE network. The new grid codes are implemented in this layer to accommodate the DGs. This is done to accomplish information acquisition and control operations. The cloud layer, which serves as the fourth layer of the substation, collects data from the CT, PT, solar power, wind power, transformers, CBs, frequency analyzer for DGs, and all other auxiliary devices. It stores all the data and uses it for data analysis.

A smart distributed substation would have to deal with variable power and frequency generated by the DG units, which can be dealt by the EVT and ECT (voltage and current transformers) in the primary equipment and the frequency analyzer present the first layer. Another challenge that this layer would have to deal with is bidirectional power flow, where consumers will both consume power from the grid, and an extra amount will be 
added to the grid via a frequency analyzer. Besides this, a robust predictive analysis of the distributed grid needs to be in place. This can be done by the acquisition of data from the IoT devices connected to the DGs and by gathering data from the environmental agency. Fault analysis would also be easier, as IoT is distributed all throughout the distribution network. Hence, one data center can work for both fault analysis and the predictability of DG output.

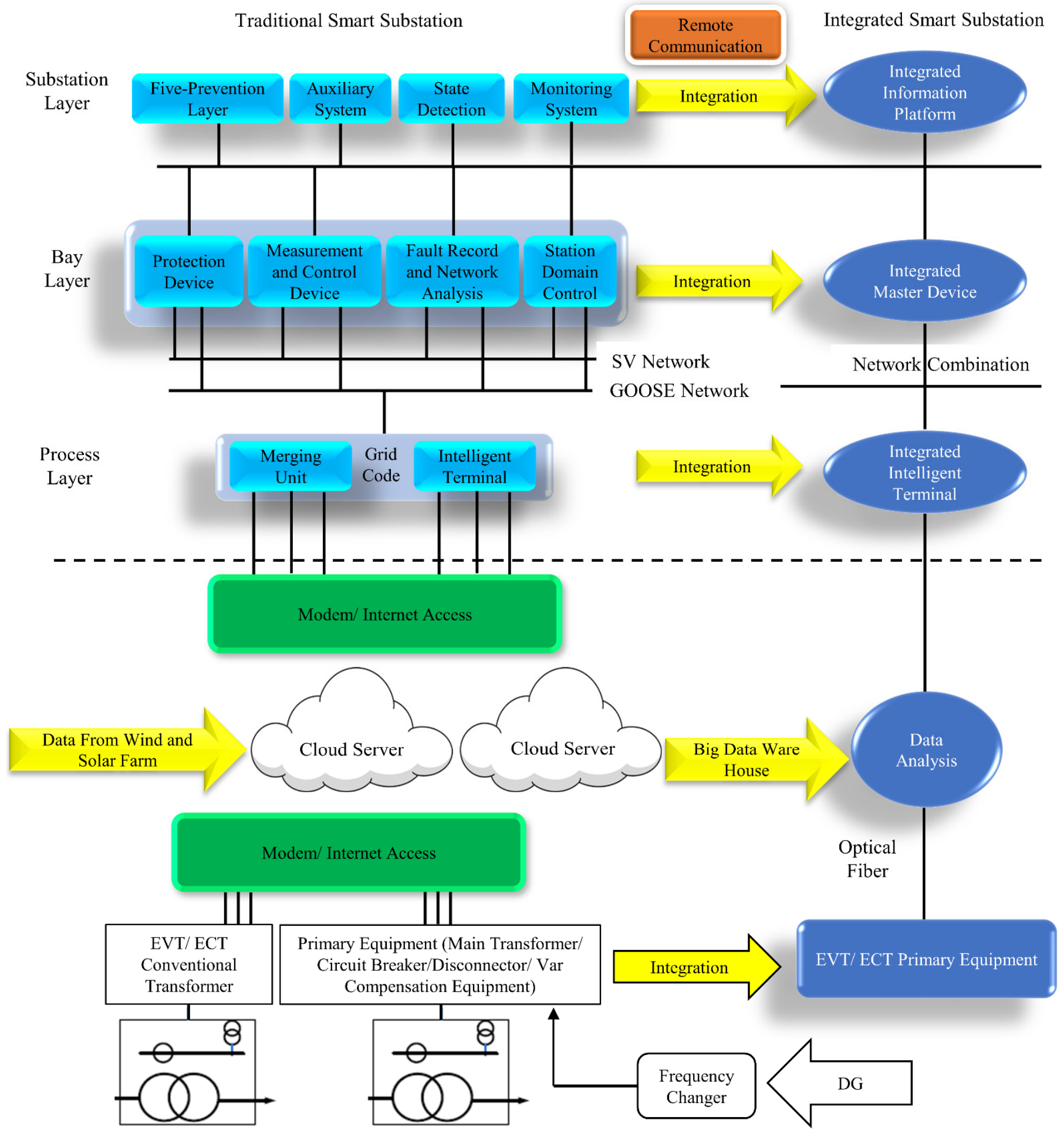

Figure 6. Overview of the proposed smart substation in Bangladesh. 


\section{Prospective Smart Substation Control Architecture in Bangladesh}

Several control centers or electric utility applications are used to automate a substation that includes supervisory control and data acquisition (SCADA), a data management system (DMS), environmental management system (EMS), automated meter reading, network integration system, geographic information system for prediction, and control [23,42]. In Figure 7, a schematic of the whole control system of the smart substation is outlined. As Bangladesh is not yet completely digitalized, a robust local network with all data storage facilities would be needed for IED. Protective relays are connected to distributed substation local area network (LAN). These would be connected to a local server and a local HMI. Then, it would be connected to a central database. Remote access should be given to the central control center, where cyber access management system, outage management system, asset management system, distribution management system, energy management system, and overwrite of control servers are located.

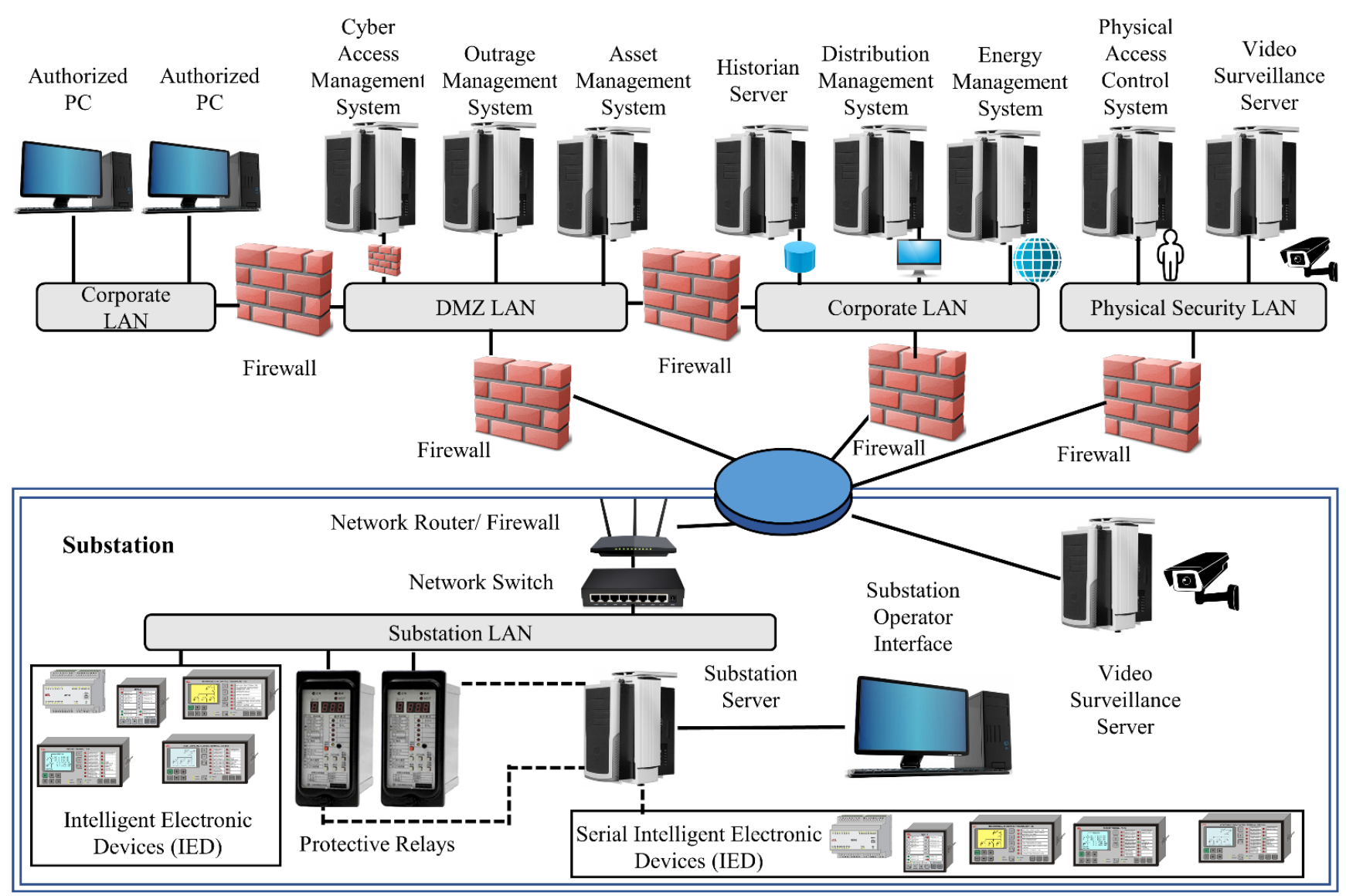

Figure 7. Prospective smart substation control scheme for Bangladesh.

This type of smart distributed substation ought to have two distinct operation modes: normal and emergency. In normal mode, the hardware should operate normally and all functions of the SCADA system must work. In emergency mode, supervisory control would take over the local network. The SCADA system would allow us to have a different management system, which helps to automate the substation and makes the network more reliable. There are several servers that would govern the automation and act as a data storage bank for the proposed distributed system. The HMI-based physical access control system is allocated for this task, which would allow the system admin to log in for any maintenance or fetching data for further analysis. The energy management system would store data for the load calculation and determine the peak load and off-peak load hours. Distribution management and asset management would have all the data 
of the components under the specific distributed substation. The information related to preventive maintenance service (PMS), reports, and certification would be stored in the asset management server. This information would be used as a health monitoring tool for transformer, $\mathrm{CB}, \mathrm{PT}$, and $\mathrm{CT}$ devices.

\section{Discussion}

This work focused on the existing power structure of Bangladesh and its potential to generate electricity from conventional and non-conventional sources. The need for a smart substation is becoming more prominent. The smart substation idea is becoming popular with utilities becoming communication enabled around the world. A huge transition in transmission and distribution system in the post-World War II eras can be seen. This is due to the fact that unparalleled growth has pushed the demand for electricity. Many leaders in that era saw the need for new technologies to play a bigger role in how the grid was controlled and managed. Similarly, in the network of tomorrow, a huge change is expected due to the change in the demography of power-producing areas. Even though the full system would take a long time to be established, a prototype implementation is quite achievable. The prototype design presented in this research can be implemented in any part of the country. Currently, Bangladesh's transmission system is at $230 \mathrm{kV}$, and it goes down to $33 \mathrm{kV}$. Then, it is routed through $11 \mathrm{kV}$ to the distribution end. The proposed substation would not require much modification from the existing BPDB substations. The existing substation power flow would remain almost the same. The main change that must be done would be from the tiebreaker on to the distribution bus. A PLL, converter, and one AC bus would need to be additionally connected, which should be connected to the distribution bus via a transformer. The PLL required for this type of system is ADALINE due to its robust behavior to the harmonics in the system. There ought to be wireless measuring devices (IoT) in this section to get the live feed to the substation control for the predictive and data analysis. Due to the simplicity of the proposed system, it would be very much possible to replicate it throughout Bangladesh. This could bring about a huge change in the power network of the country. Some key features of the proposed system are:

- $\quad$ The use of IEC 61850 and GOOSE messages to operate;

- Standardization of the interfaces between equipment;

- Incorporating of wind and solar sources directly to the $0.415 \mathrm{kV}$ bus;

- Proposed substation layout would reduce the control caballing, as many of the function are wireless;

- Integration of the new grid code to allow for the data collection for DGs;

- Fast and easy replacement of protection and control devices;

- The application of this new technology would enhance the security, control, and observability;

- Data hosting and data collection methods would allow for the substation to control the DG much more efficiently;

- IoT integration would make it easy for expansion;

- ADALINE PLL would help to reduce harmonics;

- Four-layer structure for substation architecture;

- Cloud server access for control and operation;

- Both local and supervisory control are allowed, and the inclusion of IoT would enable remote access and control by the master user;

- Remote switchgear operator;

- Remote VCB operation.

\section{Conclusions}

The increasing price of electricity, rising power demand, and significant generation deficit is driving Bangladesh to move towards renewable resources. Different types of renewable resources are now being explored and implemented as the alternative sources of energy, both in urban and rural settings. Instead of managing these systems centrally, it 
will be more effective to manage these resources in a small scale and distributed manner. A smarter substation would make the integration easier for Bangladesh. This can be achieved by making small modifications in the existing architecture. A full review of the current energy mix along with substation architecture was studied in this paper. Moreover, the study analyzed the potential of a smart substation, its required architecture, and the equipment needed for upgradation.

The paper outlines the energy mix of Bangladesh and brings about some critical changes from the existing structure. Currently, the GOOSE message is not being used in the existing substation. The paper outlines the benefit of the GOOSE message and the effectiveness of the IEC 61850 protocol. The ETAP simulation provides a concluding result to support the incorporation of wind and solar farms at $0.415 \mathrm{kV}$.

The implementation of such substations would make Bangladesh go a long way forward. A prospective four-layer architecture was proposed, which would ensure the easy integration of renewable energy into the power mix. This would also ensure the intelligent and autonomous management of supplying power from renewable resources. The control of the load side would be more efficient, and it would contribute to solve the energy crisis in Bangladesh. With predictive analysis and forecasting, it will be an effective and vigilant medium to make DG profitable. Finally, it can be said that smart substations are an essential element for a robust and expandable power supply in the future. Currently, the limitation faced by Bangladesh is the fund to create a model substation. However, with the revolutionary change in the private sector of Bangladesh, a real-time smart substation is not far away.

Author Contributions: Conceptualization, A.H.S. and M.H.; methodology, A.H.S., M.H., S.I. and K.R.; validation, A.H.S. and M.H.; formal analysis, A.H.S.; investigation, A.H.S., M.H., S.I. and K.R.; resources, A.H.S.; writing-original draft preparation, A.H.S. and M.H.; writing-review and editing, M.H., S.I. and K.R.; visualization, A.H.S. and M.H.; supervision, S.I. and K.R.; project administration, K.R.; funding acquisition, K.R. All authors have read and agreed to the published version of the manuscript.

Funding: This research received no external funding.

Institutional Review Board Statement: Not applicable.

Informed Consent Statement: Not applicable.

Data Availability Statement: No new data were created or analyzed in this study. Data sharing is not applicable to this article.

Acknowledgments: Our sincere gratitude to Sana Ullah (Executive Engineer) and A. K. M. Shamsul Arefin (Assistant Engineer) of BPDB for their technical support. Moreover, the authors are thankful to Emon Barua of Siemens Bangladesh, and Abu Bakr Siddique and Al Amin Hossain of Reverie Power and Automation Engineering, Bangladesh.

Conflicts of Interest: The authors declare no conflict of interest.

\section{References}

1. Georgilakis, P.S.; Hatziargyriou, N.D. A review of power distribution planning in the modern power systems era: Models, methods and future research. Electr. Power Syst. Res. 2015, 121, 89-100. [CrossRef]

2. Hafezi, H.; D'Antona, G.; Dedè, A.; Della Giustina, D.; Faranda, R.; Massa, G. Power Quality Conditioning in LV Distribution Networks: Results by Field Demonstration. IEEE Trans. Smart Grid 2017, 8, 418-427. [CrossRef]

3. Ratnam, K.S.; Palanisamy, K.; Yang, G. Future low-inertia power systems: Requirements, issues, and solutions-A review. Renew. Sustain. Energy Rev. 2020, 124, 109773. [CrossRef]

4. Park, J.H.; Kim, M.; Kwon, D. Security Weakness in the Smart Grid Key Distribution Scheme Proposed by Xia and Wang. IEEE Trans. Smart Grid 2013, 4, 1613-1614. [CrossRef]

5. Smith, M.D.; Paté-Cornell, M.E. Cyber Risk Analysis for a Smart Grid: How Smart is Smart Enough? A Multiarmed Bandit Approach to Cyber Security Investment. IEEE Trans. Eng. Manag. 2018, 65, 434-447. [CrossRef]

6. Zhao, L.; Matsuo, I.B.M.; Zhou, Y.; Lee, W. Design of an Industrial IoT-Based Monitoring System for Power Substations. IEEE Trans. Ind. Appl. 2019, 55, 5666-5674. [CrossRef] 
7. Siddique, A.H.; Tasnim, S.; Shahriyar, F.; Hasan, M.; Rashid, K. Renewable Energy Sector in Bangladesh: The Current Scenario, Challenges and the Role of IoT in Building a Smart Distribution Grid. Energies 2021, 14, 5083. [CrossRef]

8. Ahmed, S.; Islam, M.T.; Karim, M.A.; Karim, N.M. Exploration of renewable energy for sustainable development and overcoming power crisis of Bangladesh. Renew. Energy 2014, 72, 223-235.

9. Chowdhury, S.A.; Mourshed, M.; Kabir, S.M.R.; Islam, M.; Morshed, T.; Khan, M.R.; Patwary, M.N. Technical appraisal of solar home systems in Bangladesh: A field investigation. Renew. Energy 2011, 36, 772-778. [CrossRef]

10. Motlagh, N.H.; Mohammadrezaei, M.; Hunt, J.; Zakeri, B. Internet of Things (IoT) and the Energy Sector. Energies 2020, 13, 494. [CrossRef]

11. Masud, M.H.; Nuruzzaman, M.; Ahamed, R.; Ananno, A.A.; Tomal, A.N.M.A. Renewable energy in Bangladesh: Current situation and future prospect. Int. J. Sustain. Energy 2020, 39, 132-175. [CrossRef]

12. Bangladesh Power Development Board. Annual Report 2018-2019. Available online: https://www.bpdb.gov.bd/bpdb_new/ resourcefile/annualreports/annualreport_1574325376_Annual_Report_2018-19.pdf (accessed on 2 May 2020).

13. Bangladesh Power Development Board. Annual Report 2017-2018. Available online: http://www.bpdb.gov.bd/bpdb_new/ resourcefile/annualreports/annualreport_1542104191_Annual_Report_2017-18_2.pdf (accessed on 2 May 2020).

14. Bangladesh Power Development Board. Annual Report 2016-2017. Available online: http://archive.bpdb.gov.bd/download/ annual_report/Annual\%20Report\%202016-17\%20(3).pdf (accessed on 2 May 2020).

15. Taheruzzaman, M.; Janik, P. Electric Energy Access in Bangladesh. Trans. Environ. Electr. Eng. 2016, 1, 1-12. [CrossRef]

16. Fahim, A.; Chowdhury, M.A.; Alam, M.F.; Elahi, F.; Shourov, E.C.; Hasan, M. Smart Transformer Theft Protection and Maintenance Monitoring System. In Proceedings of the 2nd International Conference on Robotics, Electrical and Signal Processing Techniques (ICREST), Dhaka, Bangladesh, 5-7 January 2021; pp. 607-612.

17. Khan, A.H.; Islam, A.; Islam, M.; Nur, T.E.; Ghose, S. A review of electricity generation and evacuation in Bangladesh. Energy Power 2015, 5, 10-16.

18. Bangladesh Power Development Board. Bangladesh Power Production and Consumption. Available online: http://www. indexmundi.com/g/g.aspx?c=bg\&v=79 (accessed on 2 May 2020).

19. Ashraf, A.S.M.A.; Islam, M.S. Explaining public policy choices, a case study of the first nuclear power plant in Bangladesh. Strateg. Anal. 2018, 42, 503-523. [CrossRef]

20. Cárdenas, J.; Farooqui, A.L.D.V.H.; Argandoña, R.; Arriba, C.D. The next generation of Smart Substations Challenges and Possibilities. In Proceedings of the CIGRE 2012, Paris, France, 27-31 August 2012.

21. Yarali, A.; Rahman, S. Smart Grid Networks: Promises and Challenges. J. Commun. 2012, 7, 409-417. [CrossRef]

22. Heckel, J. Smart substation and feeder automation for a Smart distribution grid. In Proceedings of the 2009 CIRED-20th International Conference and Exhibition on Electricity Distribution, Prague, Czech Republic, 8-11 June 2009; pp. 1-4.

23. Huang, Q.; Jing, S.; Cai, D.; Wu, J.; Zhen, W. Smart Substation: State of the Art and Future Development. In Proceedings of the 2018 IEEE Power \& Energy Society General Meeting (PESGM), Portland, OR, USA, 5-10 August 2018; p. 1.

24. Song, Q.; Sheng, W.; Kou, L.; Zhao, D.; Wu, Z.; Fang, H.; Zhao, X. Smart substation integration technology and its application in distribution power grid. CSEE J. Power Energy Syst. 2016, 2, 31-36. [CrossRef]

25. Li, H.; Wang, L. Research on Technologies in Smart Substation. Energy Procedia 2011, 12, 113-119. [CrossRef]

26. Ahmadiahangar, R.; Rosin, A.; Palu, I.; Azizi, A. Challenges of Smart Grids Implementation. In Demand-Side Flexibility in Smart Grid; Springer: Singapore, 2020.

27. Meng, W.; Ma, R.; Chen, H. Smart grid neighborhood area networks: A survey. IEEE Netw. 2014, 28, 24-32. [CrossRef]

28. Prettico, G.; Flammini, M.G.; Andreadou, N.; Vitiello, S.; Fulli, G.; Masera, M. Distribution System Operators Observatory 2018-Overview of the Electricity Distribution System in Europe; EUR 29615 EN; Publications Office of the European Union: Luxembourg, 2019.

29. Ofualagba, G.; Akinloye, B.O. Design of A distribution station monitoring system using nigeria secondary distribution substation as a case study. Int. J. Novel Res. Eng. Sci. 2017, 4, 63-73.

30. Elizabeth, A.; Samuel, W.; Felix, A.; Simeon, M. Smart grid technology potentials in Nigeria: An Overview. Int. J. Appl. Eng. Res. 2018, 13, 1191-1200.

31. Zulfiqar, S.; Munawar, U.; Farooq, M.U. Smart grid implementation and development in Pakistan. In Proceedings of the 2017 International Conference on Energy Conservation and Efficiency (ICECE), Lahore, Pakistan, 22-23 November 2017; pp. 50-54.

32. Aboumalik, M.; El Brak, M.; Essaaidi, M. Moving toward a smarter power grid: A proposed strategy for strengthen smart grid roadmaps through a case study. Int. J. Smart Grid Clean Energy 2019, 131-139. [CrossRef]

33. Paramesha, K.; Hegde, V. Techno-economic reasons for construction of electrical substations on step-like ground surface and related open issues. In Proceedings of the 2014 6th IEEE Power India International Conference (PIICON), Delhi, India, 5-7 December 2014; pp. 1-4.

34. Müller, U.P.; Schachler, B.; Scharf, M.; Bunke, W.-D.; Günther, S.; Bartels, J.; Pleßmann, G. Integrated Techno-Economic Power System Planning of Transmission and Distribution Grids. Energies 2019, 12, 2091. [CrossRef]

35. Kumari, V.; Singh, P. Upgradation of Existing Substation into a Smart Substation. Adv. Res. 2020, 21, 50-66. [CrossRef]

36. Al-Mohaisen, A.; Chausse, L.; Sud, S. Progress Report on the GCC Electricity Grid System Interconnection in the Middle East. In Proceedings of the 2007 IEEE Power Engineering Society General Meeting, Tampa, FL, USA, 24-28 June 2007; pp. 1-7. 
37. Cebeci, M.E.; Eren, S.; Tor, O.B.; Güven, N. Transmission and substation expansion planning using Mixed Integer Programming. In Proceedings of the 2011 North American Power Symposium, Boston, MA, USA, 4-6 August 2011; pp. 1-5.

38. Morais, B.T.P. Emerging Technologies and Future Trends in Substation Automation Systems for the Protection, Monitoring and Control of Electrical Substations. Master's Thesis, Universidade do Porto, Praca de Gomes Texeira, Porto, Portugal, 2013.

39. Qi, B.; Yuan, Y.; Yang, Y.; Bu, Q.; Chen, J. Chapter 1-Overview of Smart Substations. In EC 61850-Based Smart Substations: Principles, Testing, Operation and Maintenance; Academic Press: Amsterdam, The Netherlands, 2019; pp. 1-24.

40. Ceci, M.; Corizzo, R.; Fumarola, F.; Ianni, M.; Malerba, D.; Maria, G.; Masciari, E.; Oliverio, M.; Rashkovska, A. Big data Techniques for supporting accurate predictions of energy production from renewable sources. In Proceedings of the 2015 19th International database Engineering and Applications Symposium, Jokohama, Japan, 13-15 July 2015; Association of Computer Machinery: New York, NY, USA, 2015; pp. 62-71.

41. Ali, M.N.; Nahian, A.J.; Siddique, A.H.; Hasan, M.; Chowdhury, N.; Hossain, C.A. Prospect of Mini-Hydel Power Generation in Drainage Systems of Bangladesh. In Proceedings of the 2021 2nd International Conference on Robotics, Electrical and Signal Processing Techniques (ICREST), Dhaka, Bangladesh, 5-7 January 2021; pp. 278-281.

42. Debnath, D.; Siddique, A.H.; Hasan, M.; Faisal, F.; Karim, A.; Azam, S.; Boer, F.D. Smart Electrification of Rural Bangladesh through Smart Grids. In Sustainable Communication Networks and Application. Lecture Notes on Data Engineering and Communications Technologies; Springer: Singapore, 2021. 